\title{
Article \\ Estimation of Stature from Tibia Length for Romanian Adult Population
}

\author{
Madalina Maria Diac ${ }^{1}\left(\mathbb{D}\right.$, Tatiana Iov ${ }^{2, *}$, Simona Irina Damian ${ }^{1, *}$, Anton Knieling ${ }^{1, *}$, Nona Girlescu ${ }^{3}$, \\ Codrin Lucasievici ${ }^{1}$, Sofia David ${ }^{1}$, Elena F. Kranioti ${ }^{4}{ }^{\mathbb{D}}$ and Diana Bulgaru Iliescu ${ }^{1}$ \\ 1 Forensic Science Department, University of Medicine and Pharmacy “Grigore T. Popa”, 700115 Iasi, Romania; \\ madalina-maria.diac@umfiasi.ro (M.M.D.); codrin.11994@yahoo.com (C.L.); sofia.david@umfiasi.ro (S.D.); \\ diana.bulgaru@umfiasi.ro (D.B.I.) \\ 2 Institute of Legal Medicine, 700455 Iasi, Romania \\ 3 1st Morpho-Functional Sciences Department, University of Medicine and Pharmacy "Grigore T. Popa", \\ 700115 Iasi, Romania; nona.girlescu@yahoo.com \\ 4 Forensic Medicine Unit, Department of Forensic Sciences, University of Crete, 71003 Heraklion, Greece; \\ ekranioti@uoc.gr \\ * Correspondence: iovtatiana@yahoo.com (T.I.); simona.damian@umfiasi.ro (S.I.D.); \\ anton.knieling@umfiasi.ro (A.K.)
}

check for

updates

Citation: Diac, M.M.; Iov, T.; Damian, S.I.; Knieling, A.; Girlescu, N.; Lucasievici, C.; David, S.; Kranioti, E.F.; Iliescu, D.B. Estimation of Stature from Tibia Length for Romanian Adult Population. Appl. Sci. 2021, 11, 11962. https://doi.org/ 10.3390/app112411962

Academic Editors: Rossella Bedini and Fabio La Foresta

Received: 31 October 2021

Accepted: 9 December 2021

Published: 15 December 2021

Publisher's Note: MDPI stays neutral with regard to jurisdictional claims in published maps and institutional affiliations.

Copyright: (c) 2021 by the authors. Licensee MDPI, Basel, Switzerland. This article is an open access article distributed under the terms and conditions of the Creative Commons Attribution (CC BY) license (https:// creativecommons.org/licenses/by/ $4.0 /)$.

\begin{abstract}
The estimation of stature from bones plays an important role in identifying unknown bodies, body parts, or skeletal remains, as it is an important component of the biological profile in forensic identification. The objective of this study is to enhance the development of forensic anthropology in Romania by creating a new regression formula for stature estimation. This can be accomplished from the length of the tibia, taking into account sex and age, for the Romanian adult population. A total of 137 cases from a delimited territory of Romania were included in the study. The length of the tibia and the stature of the individuals were measured before autopsy. Statistical analysis was carried using (Statistical Package for the Social Sciences) SPSS 23. Tibia length showed a high correlation with stature for males, females, and the total sample. Four regression formulae were created for stature estimation of Romanian males, females, and unknown sex. The results of the analysis are impressive and have a good applicability in a forensic anthropological context. The data used in this paper provide reliable results with a large applicability in the future for estimating stature from the tibia length for the Romanian adult population.
\end{abstract}

Keywords: stature estimation; tibia length; forensic anthropology

\section{Introduction}

Forensic anthropology makes important contributions to human identification, as well as to diagnosing the causes and mechanisms of death. The methods used involve the development of a biological profile-assessing parameters such as ethnicity, sex, stature, and age. Forensic anthropology can also identify possible bone disease or trauma [1,2].

The application of forensic anthropology is necessary and mandatory in situations dealing with complete skeletons, skeletal fragments, single bones such as skulls or mandibles with teeth, and separated teeth, as well as in situations of decomposed, fragmented, or partially skeletonized cadavers.

Stature is one of the pillars of human anthropological identification, being one of four demographic characteristics of the biological profile that can be estimated from skeletal remains. The estimation of stature helps forensic anthropologists to identify individuals of an unknown identity, as a good or, at least, fair stature estimate can narrow down the possible matches and facilitate positive identification [3-5].

Currently, at an international level, there is an increase in the importance granted to forensic anthropological identification, reflected in the multitude of scientific studies 
and on methods that help create accurate individual biological profiles from human remains [6-9]. Thus, continuous work is being carried out to develop new methods that provide information with the highest degree of accuracy and up-to-date standards for contemporary population groups $[2,8]$.

The main purpose of current research on stature estimation is based on mathematical formulas that help the forensic field to improve stature estimation methods. The literature shows an interest in specific population research (Bosnian, Turkish, and Mexican populations, etc.) [10-13].

Despite the recent developments in the forensic anthropology discipline, there are no anthropometric studies for the adult population in Romania. In this vein, the present study aims to provide standards for sex and stature estimation for contemporary Romanians using tibial length, and to set the basis for acquisition of biological data for this population that can lead to new methods for estimating other aspects of biological profile, such as age, sex, and ethnicity. The novelties of the current research compared to the existing ones, first of all and most importantly, are represented by the fact that it was performed only on the Romanian population, so it is a specific population study, and secondly, regression formulas were created that can be applied in the practice of forensic anthropology on the Romanian territory.

\section{Materials and Methods}

The study group included 137 cases represented by deceased adults, which were subjected to forensic autopsies performed in the north-east territory of Romania, in the Moldavian region. The study was a prospective one and it was conducted in accordance with the Declaration of Helsinki, and the protocol was approved by the Ethic Committee of "Grigore T. Popa" Medicine and Pharmacy University.

The inclusion criteria were represented by corpses with the absence of malformations or skeletal changes that could have influenced the size (height) of the deceased (lower limb amputations and carbonizations). Bodies with fractures of the lower limbs, those in an advanced state of putrefaction, as well as charred bodies, were excluded from this study.

Regarding the personal data retained in the study, only the sex, age, and stature (measured postmortem) were noted. Measurements of the length of the tibia were also recorded. All of the above data have been included in a database.

As a working methodology, the authors conducted the study on cadaveric material, with deceased persons whose full autopsy was mandatory. The working material was represented by the length of the tibia, one of the long bones of the human skeleton, which is representative for stature estimation, measured during the forensic autopsy.

The instruments required for measuring the tibia were an anthropological caliper (simple-beaked mechanical screw and Martin fine-tuning) for measuring with an accuracy of $0.1 \mathrm{~mm}$, as well as a graded ruler to confirm the measurement taken. To make the incision we used a scalpel.

Cases were placed on the autopsy table in the dorsal decubitus, and cadaveric stiffness was defeated in the cases in which it was present. Before the forensic autopsy was performed, the height of the deceased was measured from the calcaneus to vertex, and the sex and age were noted. All of the measurements of the length of the tibia were taken only at the level of the lower left limb, between the uppermost point of the proximal extremity of the tibia, at the level of the tibial plateau and the lowest point of the internal tibial malleolus at the distal extremity of the tibia. Subsequently, during the forensic autopsy, the joint cavity in the knee was opened to highlight the tibial plateau.

The method used to open the joint cavity in the knee followed several stages. A support stand was placed under the lower limb, in the popliteal space, with the knee semi-flexed. The tibial condyles (medial and lateral) and the patella were identified by palpation; subsequently, following a transverse line between the two condyles, an incision was made approximately $1 \mathrm{~cm}$ below the patella. To highlight the tibial plateau, the following anatomical planes were incised: the skin, the adipose subcutaneous tissue, and 
the ligament plane (cross ligament and ligament aponeurosis). Initially, measurements were made by placing the ends of the calipers on the surface of the tibial plateau and at the lower extremity of the internal malleolus - a point identified by palpation. The value obtained was compared with the results of a second measurement, for which the lowest point of the internal malleolus was obtained by an oblique incision $0.5 \mathrm{~cm}$ below the palpated landmark, from the posterior to the anterior. Thus, it was inferred that the second incision is not necessary, the two values being identical. In this respect, all measurements were made on the length of the tibia by making only the first incision, the one that highlighted the tibial plateau, and the lower extremity of the tibia was identified by palpation.

\section{Results}

The resulting database was analyzed using (Statistical Package for the Social Sciences) SPSS 23.0. Statistical analysis was carried out in three stages to check the normality of the study, to carry out a correlational analysis, as well as a mathematical analysis for the development of the regression formulas.

The research included 137 cases aged 22 to 91 years $(M=60.60, S D=16.38)$, of which 56 were female (40.9\%) between 42 and 91 years of age, with a height between 146 and $170 \mathrm{~cm}$, and 60 male cases (59.1\%), aged 22 to 86 years, with a height between 154 and $194 \mathrm{~cm}$.

\subsection{Checking the Normality of Statistical Distribution}

The Kolmorogov-Smirnov test indicated a normal distribution of the variables for the height and length of the tibia $(p>0.05)$.

The height varied between 146 and $194 \mathrm{~cm}$, and the length of the tibia varied between 30.05 and $47.10 \mathrm{~cm}$ (Table 1). The results are presented separately for male and female participants in Table 1.

Table 1. Descriptive statistics of height and tibia length, as well as separately for females and males.

\begin{tabular}{ccccccc}
\hline Measurements $(\mathbf{c m})$ & Sex & N & Min & Max & Mean & SD \\
\hline Height $(\mathrm{cm})$ & - & 137 & 146 & 194 & 167.56 & 10.24 \\
Tibia length $(\mathrm{cm})$ & - & 137 & 30.05 & 47.10 & 36.92 & 2.72 \\
Height $(\mathrm{cm})$ & Female & 56 & 146 & 179 & 161.13 & 8.28 \\
- & Male & 81 & 151 & 194 & 172.01 & 9.06 \\
Tibia length $(\mathrm{cm})$ & Female & 56 & 30.05 & 40.50 & 35.33 & 2.47 \\
- & Male & 81 & 32.90 & 47.10 & 38.02 & 2.32 \\
\hline
\end{tabular}

The T-test showed significant differences between males and females in height $(\mathrm{t}(135)=7.151, p<0.001)$. In this respect, male stature $(\mathrm{M}=172.01, \mathrm{SD}=9.06)$ was significantly higher than that of female stature $(\mathrm{M}=161.13, \mathrm{SD}=8.28)$.

The Pearson correlation indicated a strong significant negative link $(\mathrm{r}(135)=-0.508$, $p<0.001$ ). In this respect, the higher the age of the participants, the lower their height, which is in accordance with reality, due to all of the processes that intervene in statural regression during each individual's life.

\subsection{Correlational Analysis}

The statistical analysis indicated a very strong significant correlation between the tibia length and stature $(\mathrm{r}(135)=0.878, p<0.001)$. In this respect, the longer the tibia, the higher the stature (Table 2). 
Table 2. Correlation and partial correlation (controlling the sex and age of the participants) between tibia length and height.

\begin{tabular}{ccc}
\hline- & $\begin{array}{c}\text { Height } \\
\text { (Correlation) }\end{array}$ & $\begin{array}{c}\text { Height } \\
\text { (Partial Correlation) }\end{array}$ \\
\hline Tibia length & $0.878^{* *}$ & $0.827^{* *}$ \\
\hline${ }^{* *}$ Indicates significance at the 0.01 level. & &
\end{tabular}

The partial correlation between the length of the tibia and height was also analyzed by controlling the sex and age of the participants.

The results indicate a very strong significant link between the length of the tibia and height, by controlling the sex and age of the participants ( $\mathrm{r}(131)=0.827, p<0.001$; Table 2).

\subsection{Regression Analysis}

3.3.1. Regression Analysis with Sex and Age

The regression analysis showed that the tibia length, sex, and age formed a pattern of statistically significant regression $(\mathrm{F}(3,133)=196.916 p<0.001)$, which explained a proportion of $81.6 \%\left(R^{2}=0.816\right)$ of the stature variance. An analysis of the predictors that contribute to the efficiency of the model was carried out.

Within the predictive model, the most important predictor of stature is tibia length ( $\beta=0.753, p<0.001)$, followed by the age $(\beta=-0.200, p<0.001)$ and sex of the subjects $(\beta=0.102, p=0.019<0.05)$.

We found that sex and age predicted $42 \%$ of the height variance $\left(R^{2}=0.420, p<0.001\right)$, and the length of the tibia brought a significant addition of $39.6 \%\left(R^{2}\right.$ change $=0.396$, $p<0.001$ ).

The regression equation (Table 3):

Stature $1=69.283+2.833 x /{ }^{*}$ tibia length $-0.125 x /{ }^{*}$ age $+2.119 x /{ }^{*} \operatorname{sex}$,

For sex: male is represented by code 1 and female by code 0 .

All of the conditions of multiple linear regression were met.

\subsubsection{Regression Analysis with Unknown Age and Sex}

The regression analysis showed that the length of the tibia statistically predicted the height $(\mathrm{F}(1,135)=452.995 p<0.001)$ and explained a proportion of $77 \%\left(R^{2}=0.770\right)$ of the variance of height.

Regression equation (Table 3):

$$
\text { Stature } 2=45.708+3.3 x /{ }^{*} \text { tibia length }
$$

All of the conditions of the simple linear regression formula were met.

\subsubsection{Regression Analysis with Known Sex}

The regression analysis showed that the length of the tibia and sex formed a pattern of regression that was statistically significant $(\mathrm{F}(2,134)=240.791 p<0.001)$, which explains a proportion of $78.2 \%\left(R^{2}=0.782\right)$ from the variance of height.

The following is the analysis of the predictors that contributed to the efficiency of the model. Within the predictive model, the most important predictor of height is the length of the tibia ( $\beta=0.817, p<0.001)$, followed by the sex of the participants $(\beta=0.125$, $p=0.008<0.05)$.

We found that sex predicted $27.5 \%$ of the height variance $\left(R^{2}=0.275, p<0.001\right)$ and the tibia length brought a significant explanatory addition of $50.8 \%\left(R^{2}\right.$ change $=0.508$, $p<0.001$.

Regression equation (Table 3):

$$
\text { Stature } 3=52.661+3.07 \mathrm{x} /{ }^{*} \text { tibia length }+2.595 \mathrm{x} /{ }^{*} \mathrm{sex} \text {, }
$$

For sex: male is represented by code 1 , and female by code 0 . 
All of the conditions of multiple linear equations were met.

\subsubsection{Regression Analysis with Known Age}

The regression analysis showed that the length of the tibia and age formed a pattern of regression that was statistically significant $(\mathrm{F}(2,134)=282.659 p<0.001)$, which explained a proportion of $80.6 \%\left(R^{2}=0.808\right)$ from the variance of the stature.

Then, we carried out an analysis of the predictors that contributed to the efficiency of the model. Within the predictive model, the most important predictor of height was the length of the tibia $(\beta=0.799, p<0.001)$, followed by the age of the participants $(\beta=-0.210$, $p<0.001$ ).

We found that the age predicted $25.8 \%$ of the height variance $\left(R^{2}=0.258, p<0.001\right)$, and the length of the tibia brought a significant addition of $55 \%\left(R^{2}\right.$ change $\left.=0.550, p<0.001\right)$.

Regression equation (Table 3):

$$
\text { Stature } 4=64.537+3.006 x /{ }^{*} \text { tibia length }-0.131 x / \text { age }
$$

All of the conditions of multiple linear regression were met.

Table 3. Regression equations showing the correlation between coefficients $(R)$ and the linearity of relationship $\left(\mathrm{R}^{2}\right)$.

\begin{tabular}{|c|c|c|c|c|c|}
\hline $\begin{array}{c}\text { Predicted } \\
\text { Dimension }\end{array}$ & $\begin{array}{l}\text { Simplified } \\
\text { Equation }\end{array}$ & $\mathbf{R}$ & $\mathbf{R}^{2}$ & $\begin{array}{l}<2.5 \mathrm{~mm} \\
\text { Error }(\%)\end{array}$ & $\begin{array}{c}<5 \mathrm{~mm} \\
\text { Error }(\%)\end{array}$ \\
\hline 1. Stature 1 & $\begin{array}{l}69.283+2.833 x /{ }^{*} \text { tibia length } \\
-0.125 x /{ }^{*} \text { age }+2.119 x /{ }^{*} \text { sex }\end{array}$ & $0.903^{* *}$ & 0.816 & $98.54 \%$ & $100 \%$ \\
\hline 2. Stature 2 & $45.708+3.3 x /{ }^{*}$ tibia length & $0.878^{* *}$ & 0.770 & $100 \%$ & $100 \%$ \\
\hline 3. Stature 3 & $\begin{aligned} 52.661 & +3.07 \mathrm{x} /{ }^{*} \text { tibia length } \\
& +2.595 \mathrm{x} /{ }^{*} \operatorname{sex}\end{aligned}$ & $0.884^{* *}$ & 0.782 & $100 \%$ & $100 \%$ \\
\hline 4. Stature 4 & $\begin{aligned} 64.537 & +3.006 \mathrm{x} /{ }^{*} \text { tibia length } \\
& -0.131 \mathrm{x} /{ }^{*} \text { age }\end{aligned}$ & $0.899 * *$ & 0.808 & $98.54 \%$ & $100 \%$ \\
\hline
\end{tabular}

\section{Discussion}

Estimating the human stature from bones plays a leading and important role in the reconstruction of biological profiles and subsequently in the identification of skeletal bodies, skeletal fragments, and bodies with soft tissue but with an unknown identity.

A critical analysis of the existing literature on anthropological studies highlights the most important issue discussed globally today, namely the problem of human skeletal collections, excellent sources for quantifying research in the field of forensic anthropology. The skeletal collections are also necessary for each population, making it important for these to be as complete as possible, involving the presence of both cranial and postcranial skeletons $[14,15]$. Another important reason for each population to own their own collection and implicitly their own research in the field of forensic anthropology is as a result of intense population migration. The above reason is also reflected in the main idea that the old studies carried out are no longer applicable, with the current population being a modern population with a completely different lifestyle in the context of major climate change, all of which contribute to important anthropological changes [16,17].

The "Map of Identified Osteological Collections" developed by the European Society of Forensic Anthropology highlights the presence on Romanian territory of a skeletal collection represented exclusively by skulls $[14,15]$. Thus, the lack of research in the field of forensic anthropology can be attributed to the lack of a postcranial skeletal collections. In this context, it becomes essential for research in the field of forensic anthropology to develop new methods using the bodies of deceased persons (cadavers), X-rays, or computer scans, which are validated as viable techniques that provide a wealth of information [10-13].

Previous research highlights two main methods of estimating stature: an anatomical method and a mathematical one [1,2]. The anatomical method involves reconstituting the stature by adding bone measurements of various skeletal elements between the skull and 
the leg and adding constants for soft tissue. Despite the numerous studies carried out over the years for improving the accuracy of the anatomical method, it is still controversial and has some disadvantages. The most important one is the fact that forensic anthropologists must have the entire skeleton available or as many bone elements as possible. Another disadvantage of the anatomical method is that it requires a longer time to be applied. The anatomical method is preferred in archaeological cases, when complete skeletons are available [18-20].

Under these circumstances, the mathematical method, by comparison, most often becomes the preferred method for estimating stature from skeleton fragments, complete skeletons, or fresh cadaveric remains. Unlike the anatomical method, the mathematical method uses regression formulas based on the correlation between the dimensions of individual skeletal elements and the measured stature (living stature) [19-21]. According to the existing literature, there are a lot of studies that use the mathematical method based on various and different materials and methods [10-13]. Table 4 shows comparative aspects between the studies from the literature and our study [10-13].

According to the comparative aspects above, we can say that our study results show a better estimation of stature based on tibial length and compared to other studies that also used cadaveric material, the study group in the present research was larger (137 compared with 50 and 86 , respectively), so our results are more reliable.

Based on the literature, the mathematical method exhibits several advantages as it requires a short time for application, involves development of new regression formulas based on a single skeletal element (preferably long bones), and frequently age does not have a predictive value in stature estimation [22,23].

The above-mentioned advantages require some additions: Firstly, it is mandatory for each population to present its own regression formula based on the correlation between population-specific measurements and stature. It is also necessary for each population to have research carried out in this regard, involving the measurement of as many long bones as possible and subsequently creating a correlation of these measurements with the stature of the persons involved.

Given that in the forensic context, forensic specialists and forensic anthropologists are faced with cases involving skeletal remains and skeletal fragments, it goes without saying that the mathematical method is gaining ground and is being widely used.

In the current paper, the authors chose the mathematical method for estimating the stature for the adult population of Romania, developing a regression formula based on the length of the tibia.

The cadaveric material included in the study is an important source of research in forensic anthropology, as it allows researchers to work on known parameters, in this case the height, sex, and age of deceased persons.

The above-mentioned working methodology is the basis for choosing the mathematical method of height estimation, which involves the development of regression formulas based on the measured length of the tibia with the introduction or not of predictive parameters. The importance of the mathematical method is given by the fact that in the forensic context, bone fragments are often discovered, which are the subject of forensic anthropological expertise. In this respect, applying the mathematical method by introducing as many measurements of long bones as possible is of paramount in current forensic anthropology.

Tibial length was chosen as the working material by the authors because multiple studies showed that it allows for stature estimations with an increased degree of accuracy. Some studies have shown that long bones are the best choice for stature estimation and among these, the tibia is considered to be the most reliable. The authors aim to carry out further research focusing on the measurements of other long bones [22-24]. 
Table 4. Comparative aspects between the stature estimation.

\begin{tabular}{|c|c|c|}
\hline Article & Material and Method & Results \\
\hline $\begin{array}{l}\text { Menendez } \\
\text { Garmendia A. et al. } \\
\text { (2018) [11] }\end{array}$ & $\begin{array}{l}86 \text { cadavers ( } 56 \text { males and } \\
30 \text { females) measuring the } \\
\text { humerus, femur, and tibia } \\
\text { lengths-Mexican population }\end{array}$ & $\begin{array}{c}\text { R-square (males) for femur }=0.621 \\
\text { humerus }=0.687, \text { and tibia }=0.732 \\
\text { R-square (females) for humerus }=0.577, \\
\text { femur }=0.673, \text { and tibia }=0.502\end{array}$ \\
\hline $\begin{array}{l}\text { Saco-Ledo G. et al. } \\
\text { (2019) [10] }\end{array}$ & $\begin{array}{l}249 \text { Spanish Caucasian adult } \\
\text { male participants (living } \\
\text { subjects) measuring the tibial } \\
\text { length (the distance between } \\
\text { tibial medial and } \\
\text { sphyrion tibial) }\end{array}$ & $\begin{array}{l}\text { The study lot was categorized in three } \\
\text { sub-groups based on tibial length } \\
\text { according to the fact the body } \\
\text { proportions vary in short, } \\
\text { medium and tall individuals } \\
\text { as result, R-square varied between } \\
0.22 \text { and } 0.57 \text {, respectively } 0.36 \text {, and } \\
\text { R-square for all participants was } 0.77 \text {. }\end{array}$ \\
\hline $\begin{array}{l}\text { Sarajlic N. et al. } \\
\text { (2006) [12] }\end{array}$ & $\begin{array}{l}50 \text { Bosnian male cadavers } \\
\text { measuring the femur, tibia, } \\
\text { and fibula }\end{array}$ & $\begin{array}{l}\text { In this study, the authors created seven } \\
\text { formulas for stature estimation, one for } \\
\text { each tibia, femur and fibula separately } \\
\text { and other } 2 \text { using the sum between the } \\
\text { femur and tibia, respectively fibula, } \\
\text { and the last two using a multiplication } \\
\text { between femur and tibia, respectively } \\
\text { fibula. As a result, R was between } \\
0.83-0.90 \text {, but we cannot see the } \\
\text { R-square. }\end{array}$ \\
\hline $\begin{array}{l}\text { Duyar I. et al. } \\
\text { (2003) [13] }\end{array}$ & $\begin{array}{l}121 \text { Turkish males (living } \\
\text { subjects) measuring the } \\
\text { tibia length }\end{array}$ & $\begin{array}{l}\text { The group study was categorized in } \\
\text { three sub-group according to each type } \\
\text { of stature (short, medium, and tall); as a } \\
\text { result, the authors created four } \\
\text { regression formulas, one for each group } \\
\text { and the fourth as a general formula; the } \\
\text { R-square was between } 0.444-0.645 \text { and } \\
\text { the total R-square was } 0.816\end{array}$ \\
\hline Our study & $\begin{array}{l}137 \text { Romanian adults } \\
\text { represented by cadavers } \\
\text { measuring the tibia length }\end{array}$ & $\begin{array}{l}\text { As result, we created four formulas for } \\
\text { stature estimation based on tibia length, } \\
\text { one formula for the situation when the } \\
\text { age is known, another one for situation } \\
\text { when the sex is known, the third one } \\
\text { for when both (age and sex) are known, } \\
\text { and the last regression formula in the } \\
\text { situation when just the tibia length is } \\
\text { known; the R-square was between } \\
0.770 \text { and } 0.816 \text {. }\end{array}$ \\
\hline
\end{tabular}

Some authors have noted that the height of the deceased would be slightly larger than the one recorded during their lifetime, but other authors noted that due to thanatological changes, namely dehydration, the height would be about $2 \mathrm{~cm}$ smaller than the one recorded during their lifetime [25-27]. This, of course, should be subjected to further research, as even the stature of a living person may vary depending on age, bone pathologies present, etc. In addition, in the cases that formed the present study group, we did not have the stature recorded antemortem, so we cannot specify the differences between the measured stature postmortem and the antemortem one.

The objective initiated in this research was achieved, a regression formula being developed to predict the height of a person based on the length of the tibia. Thus, the present research is an important contribution in the field of forensic anthropology.

The results from the analysis are impressive and have a good applicability in a forensic anthropological context. 
The statistical analysis indicated a normal distribution of the variables involved in this study: the person's height as well as the length of tibia. There was also a strong correlation between the length of the tibia and the height of the persons, which confirmed that the tibia, as a long bone, is an important indicator in the estimation of stature (height). At the same time, there were significant differences between the age of the participants and the height - the higher the age, the lower the height and between the sex of the participants and the stature-with males being taller than women.

For a good highlight of the simple link between the stature (height) of the persons and the length of the tibia [28], as well as the link between the stature and the length of the tibia by controlling the sex and age of the participants, several regression formulas were developed.

In the field of forensic anthropology, sex and age are two parameters involved in creating a biological profile of an individual with an unknown identity [28]. These parameters are still difficult to estimate, especially when dealing with disparate bones and not with the entire skeleton; even in the presence of an entire skeleton, age is difficult to estimate.

In this context, we first developed a regression formula to estimate the height based on the tibia length, without taking into account the two predictive parameters (sex and age), the statistical analysis showing a strong correlation between tibia length and stature.

In the first situation, the one in which the sex and age of the participants were not involved, it was revealed that only the length of the tibia statistically predicted the height, explaining a proportion of $77 \%$ of the height variance. In this respect, we could predict the stature of a person with an unknown identity in a percentage of $77 \%$ based only on the length of that person's tibia.

After analyzing the partial correlation between the length of the tibia and the stature by controlling the sex and age of the participants, a very strong significant link was indicated between tibia length and stature by controlling the two predictive parameters (sex and age). The regression analysis showed that the length of the tibia, along with sex and age, could explain $81.6 \%$ of the height variance. This means that a person's height can be predicted based on the length of the tibia and taking into account both sex and age, as predictor parameters, with a high percentage of $81.6 \%$.

In a second situation, the two parameters were taken into account, one at a time, and regression formulas were developed for each of the two sub situations. So, a first regression analysis showing that the length of the tibia and the sex formed a statistically significant regression pattern, which explained a proportion of $78.2 \%$ of the height variance, and a second regression analysis showing that the length of the tibia and age also formed a statistically significant regression pattern, which explained a proportion of $80.6 \%$ of the height variance.

The concluded aspects following our research could greatly help forensic anthropology, as if neither of the two parameters (sex and age) are known, the height (stature) can still be estimated based on the tibia length at a high percentage of $77 \%$, which is not far off from the results of the other three regression formulas, offering predictions of 78.2, 80.6, and $81.6 \%$, respectively.

The results show that sex leads to a height estimation with a percentage of $78.2 \%$; age, as a predictor parameter, provides $80.6 \%$, proving that it is a stronger indicator than sex. Both percentages increase to $81.6 \%$ when taking into account both predictive parameters (sex and age), the two together becoming a much stronger indicator with the best accuracy for stature estimation.

The strengths and limitations of the current study are represented below in Table 5 .

The mathematical method that was used in this paper is highly applicable in future research in the field of forensic anthropology, as the current forensic anthropological practice carries out its activity mostly with bone fragments, not with whole skeletons. 
Table 5. Strengths and limitations of the current study.

\begin{tabular}{ll}
\hline \multicolumn{1}{c}{ Strengths of the Study } & \multicolumn{1}{c}{ Limitations of the Study } \\
\hline - A high number of participants included in the & \\
study (137 cases) & \\
- A population specific study: the research being & \\
performed on romanian adults & \\
- Created a new database regarding the stature estimation & - The measurements were taken just at \\
- The results consisted of four regression formulas: & the left tibia, and we did not perform a \\
with no age or sex known, with sex known, with age & $\begin{array}{l}\text { comparative measurement between the } \\
\text { known, or with age and sex both known }\end{array}$ \\
- All four regression formulas provided a good & \\
percentage, with r-square between 0.770 and 0.816, & \\
aspects that indicated a good applicability in the & \\
forensic practice & \\
\hline
\end{tabular}

\section{Conclusions}

The results from this research are important, we created four regression formulas for stature estimation in Romanian adults based on tibia length, which showed a high correlation with stature for males, females, and for the total sample.

The data used in this paper provide reliable results with a large applicability in the future for estimating the stature from tibia length for Romanian adult population. Future research should be done based on the measurements of more bones and also from radiographs or computer scans.

This paper is a good start in development of the forensic anthropology studies for Romanian adult populations.

Author Contributions: Conceptualization, M.M.D., E.F.K. and D.B.I.; methodology, M.M.D., C.L., S.I.D. and E.F.K.; software, M.M.D., N.G., A.K. and T.I.; validation, E.F.K. and D.B.I.; writing-original draft preparation, M.M.D. and S.I.D.; writing-review and editing, M.M.D., T.I., and S.D.; supervision, E.F.K. and D.B.I. All authors have read and agreed to the published version of the manuscript.

Funding: This research received no external funding.

Conflicts of Interest: The authors declare no conflict of interest.

\section{References}

1. Konigsberg, L.W.; Jantz, M.L. Multivariate regression methods for the analysis of stature. In New Perspectives in Forensic Human Skeletal Identification; Latham, K., Bartelink, E., Finnegan, M., Eds.; Academic Press: Cambridge, MA, USA, 2018 ; pp. $293-347$.

2. Iscan, M.Y.; Steyn, M. The Human Skeleton in Forensic Medicine, 3rd ed.; Charles C Thomas: Springfield, IL, USA, $2013 ;$ pp. 3-258.

3. Raxter, M.H.; Ruff, C.B. Full skeleton stature estimation. In New Perspectives in Forensic Human Skeletal Identification; Lathmam, K., Barteling, E., Finnegan, M., Eds.; Elsevier: London, UK, 2018; pp. 105-114.

4. Hauser, R.; Smolinski, J.; Gos, T. The estimation of stature on the basis of measurements of the femur. Forensic. Sci. Int. 2005, 147, 185-190. [CrossRef]

5. Giroux, C.L.; Wescott, D.J.; Wescott, B.A. Stature estimation based on dimensions of the bony pelvis and proximal femur. J. Forensic. Sci. 2008, 53, 65-68. [CrossRef]

6. Kranioti, E.F.; Paine, R.R. Forensic anthropology in Europe: An assessment of current status and application. J. Anthropol. Sci. 2011, 89, 71-92.

7. Blau, S.; Briggs, C.A. The role of forensic anthropology in Disaster Victim Identification (DVI). Forensic. Sci. Int. 2011, 205, 29-35. [CrossRef]

8. Cattaneo, C. Forensic anthropology: Developments of a classical discipline in the new millennium. Forensic. Sci. Int. 2007, 165, 185-193. [CrossRef] [PubMed]

9. Traithepchanapai, P.; Mahakkanurkrauh, P.; Kranioti, E.F. History, research and practice of forensic anthropology in Thailand. Forensic. Sci. Int. 2016, 261, 1-6. [CrossRef] [PubMed]

10. Saco-Ledo, G.; Porta, J.; Duyar, I.; Mateos, A. Stature estimation based on tibial length in different stature groups of Spanish males. Forensic. Sci. Int. 2019, 304, 1-8. [CrossRef] [PubMed]

11. Menendez Garmendia, A.; Sanchez-Mejorada, G.; Gomez-Valdes, J.A. Stature estimation formulae for Mexican contemporary population: A sample-based study of long bones. Forensic. Sci. Int. 2018, 54, 87-90. [CrossRef] 
12. Sarajlic, N.; Cihlarz, Z.; Klonowski, E.E.; Selak, I. Stature estimation for Bosnian male population. Bosn. J. Basic Med. Sci. 2006, 6, 62-67. [CrossRef]

13. Duyar, I.; Pelin, C. Body height estimation based on tibia length in different stature groups. Am. J. Phys. Anthro. 2003, 122, 23-27. [CrossRef]

14. The Map of Identified Osteological Collections. Forensic Anthropology Society of Europe (FASE). Available online: https: $/ /$ www.google.com/maps/d/edit?mid=162_ElRDZuDCJfM10jCkPpRSFPSw\&ll=31.412645801177902\%2C0\&z=2 (accessed on 23 July 2021).

15. Santos, A.L. A particular heritage-the importance of identified osteological collections. Met. Sci. Stud. J. 2020, 10, 91-97.

16. Lei, G.; Liu, F.; Liu, P.; Zhou, Y.; Jiao, T.; Dang, Y.H. Worldwide tendency and focused research in forensic anthropology: A bibliometric analysis of decade (2008-2017). Leg. Med. 2019, 37, 67-75. [CrossRef]

17. Iscan, M.Y. Forensic anthropology of sex and body size. Forensic. Sci. Int. 2005, 147, 107-112. [CrossRef]

18. De Angelis, D.; Messina, C.; Sconfienzo, L.; Sardanelli, F.; Cattaneo, C.; Gibelli, D. Radiology in Forensic Medicine: From Identification to Post-Mortem Imaging; Springer: Basel, Switzerland, 2019; pp. 15-87.

19. Fully, G. Une nouvelle methode de determination de la taille. Ann. Med. Leg. 1960, 40, 266-273.

20. Fully, G.; Pineau, H. Determination de la stature au moven du squelette. Ann. Med. Leg. 1960, 40, 145-154.

21. Raxter, M.H.; Ruff, C.B.; Auerbach, B.M. Technical note: Revised Fully stature estimation technique. Am. J. Phys. Anthropol. 2007, 133, 817-818. [CrossRef]

22. Auerbach, B.M.; Ruff, C.B. Stature estimation formulae for indigenous North American populations. Am. J. Phys. Anthropol. 2010, 141, 190-207. [CrossRef] [PubMed]

23. Vercellotti, G.; Agnew, A.M.; Justus, H.M.; Sciulli, P.W. Stature estimation in an Early Medieval Polish population: Testing the accuracy of regression equations in a bioarchaelogical sample. Am. J. Phys. Anthropol. 2009, 140, 135-142. [CrossRef]

24. Trotter, M.; Gleser, G.C. A re-evaluation of estimation of stature based on measurements of stature taken during life and of long bones after death. Am. J. Phys. Anthropol. 1958, 16, 79-123. [CrossRef]

25. Mantilla, H.J.C.; Cardenas, D.N.; Jacome, B.J.M. Estimacion de la talla a partir de la medida de la tibia en; plobacion colombiana. Int. J. Morphol. 2009, 27, 305-309.

26. Garmendia Menendez, A.; Gomez-Valdes, J.A.; Hernandez, F.; Wesp, J.K.; Sanchez-Mejorada, G. Long bone (humerus, femur, tibia) measuring procedure in cadavers. J. Forensic. Sci. 2014, 59, 1325-1329. [CrossRef] [PubMed]

27. Genoves, S. Proportionality of the long bones and their relation to stature among Mesoamericans. Am. J. Phys. Anthropol. 1967, 26, 67-78. [CrossRef] [PubMed]

28. Chibba, K.; Bidmos, M.A. Using tibia fragments from South Africans of Europeans descent to estimate maximum tibia length and stature. Forensic. Sci. Int. 2007, 169, 145-151. [CrossRef] [PubMed] 